\title{
PHYSIOTHERAPY IN THE REHABILITATION OF PARAPLEGIC AND QUADRAPLEGIC PATIENTS
}

\author{
By \\ P. M. DAVIES, M.C.S.P., DIP. PHYS. ED. \\ (Senior Physiotherapist. Paraplegic Unit, Conradie Hospital)
}

The rehabilitation of the paraplegic must begin from the moment he is admitted to hospital. Complications arise frighteningly early and every one of them delays the patient's eventual discharge as an independent, useful human being. Physiotherapy plays an important part in the treatment of these patients but team-work is essential for successful rehabilitation. How hopeless is the task of the physiotherapist who struggles on with a patient who is constantly ill with bladder infection, watching his pressuresores enlarge daily despite her futile attempts with ultra-violet therapy, and fighting an endless battle to have the patient dry and not embarrassed by faecal incontinence.

At the Conradie Hospital we have managed to achieve team-work in our Paraplegic Unit and I describe, therefore, physiotherapy treatment made easy by the co-operation and efforts of the other members of the team.

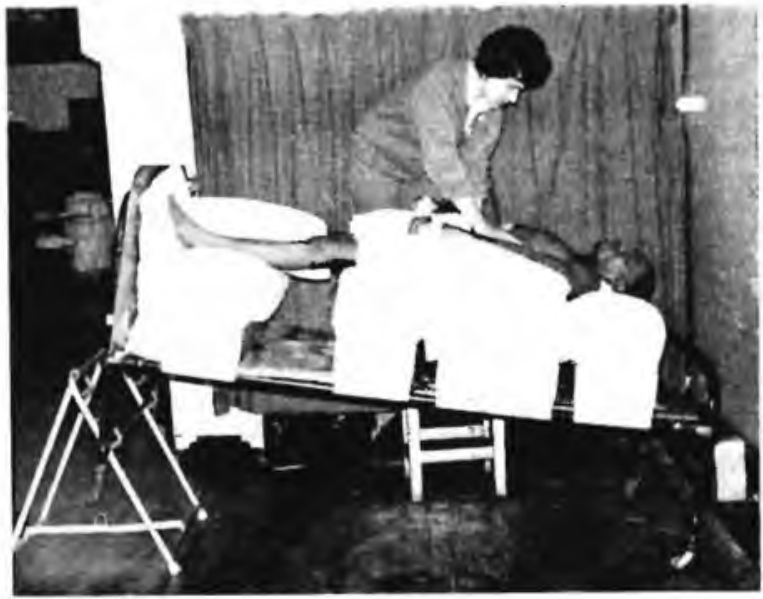

FIG. 1

Three days after injury a patient with severe dislocation of $\mathrm{C} 7$ on $\mathrm{T} 1$ is shown on special foam rubber packs, being helped to cough by a physiotherapist.

\section{PART 1}

Early Treatment :

(a) Cervical Cord Lesions

\section{The Chest}

When a quadraplegic is admitted to the Unit the physiotherapist is notified immediately so that she may help with any respiratory distress and prevent later respiratory complications. The patient is breathing solely with his diaphragm and is unable to cough or expel secretions by nose-blowing or clearing his throat, owing to the paralysis of his abdominal muscles.

Within a few hours a nasal congestion occurs due to excess secretion of the nasal mucosa following his injury, hampering his breathing and if the secretions in his lungs are not expelled, a hypo-static pneumonia or atelectasis can soon develop.

The physiotherapist here acts as abdominal muscles for the patient and by applying firm, quick pressure to his lower ribs and abdomen can enable the patient to cough or blow his nose. (Fig. 1.)
Elevating the foot of the bed and regular turning (our patients are turned every two hours) help 10 drain these secretions. This form of physiotherapy is carried out every hour or so during the day and if necessary during the night, before and after turns. Counter pressure applied by an assistant helps to give a stronger cough and also avoids moving the unstable dislocation in the cervical region.

Percussion and vibrating also help to free the secretions and make coughing easier.

We find frequently that cervicals suffer acute bronchospasm when they have developed a "wet chest" and this prevents productive coughing. Aminophyllin intramuscularly or in suppository form is most effective for relieving this.

\section{Passive Movements}

Within 24 hours the physiotherapist begins daily passive movements to all joints. These are best done while the patient is lying on his back. To affect circulation and prevent painful stiffness, each movement should be done at least 20 times.

With a cervical cord lesion the most important movements are full elevation of the shoulder, which incorporates the rotations if done in a diagonal pattern, and a full stretch of the flexor groups of the arm. To do this the shoulder and elbow must be extended and forearm fully pronated to place biceps on the stretch, and then the wrist dorsi-flexed and fingers extended simultaneously. The thumb should be moved into full abduction and extension too, to allow for a trick grip later. Such a grip is obtained by first plantarflexing the wrist, when the fingers and thumb extend, and then when an object such as a glass is between first finger and thumb, dorsi-flexion of the wrist by extensor carpi radialis holds it by placing tension on the flexors.

Trapezius is usually fully enervated in cervicals, while the depressors of the shoulder girdle may be paralysed. Care must be taken that the active trapezius does not shorten by the patient's lying with his shoulders elevated during his period of bedrest, and it should be stretched daily.

Full range movements to the lower limbs help to prevent thrombosis while avoiding contractures. Positioning of the patient by the nursing staff is important if contractures are to be avoided, particularly when spasm is present. The feet should be held in the dorsi-flexed position by a footboard and pillows; the knees held in extension, tied with a drawsheet if necessary.

When a quadraplegic has spastic biceps or persists, during the early days, in flexing his elbows, the arms should be tied down by means of a drawsheet over the wrists, until he has learnt to straighten his arms by himself, using a trick movement. 


\section{Active Movements}

Active and resisted active movements are given to strengthen the remaining enervated muscles. Care must be taken that the patient does not move his neck or affect the dislocation by too much resistance being given.

\section{Electrical Stimulation}

Faradic or galvanic stimulation to temporarily paralysed muscles helps to prevent wasting, relieve oedema and hasten re-education of recovering muscles by proprioception.

- Where the cord lesions may be incomplete, we give this form of treatment to important groups such as triceps, extensor carpi radialis and quadriceps and the anterior tibial group in the leg.

\section{(b) Thoracic and Cauda Equina Lesions}

Passive movements are again started within the first 24 hours and the rule of $\mathbf{2 0}$ times for each movement followed.

Full passive flexion of the hip is avoided because of the danger of flexing the spine at the same time. We usually limit flexion to $40^{\circ}$. All the other movements are done through a full range.

The most important movements here are full hip extension, which must be done while the patient is in the sidelying position, and lateral rotation of the hip. Hip extension is essential later to enable the patient to balance while standing, lateral rotation will facilitate activities such as putting on his shoes. Foot and toe movements must not be neglected as pressure sores form easily on clawed toes when shoes are worn later.

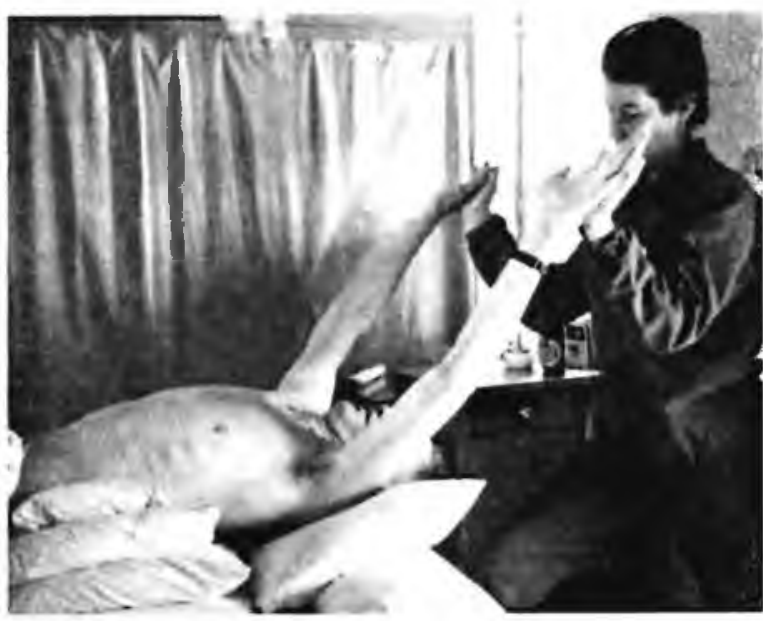

FIG. 2

A patient with a recent fracture dislocation of T11 on T12, while being nursed in hyper-extension does manually resisted bilateral arm exercises.

\section{Active Movements}

Active resisted movements are given to the upper limbs, and if done bilaterally do not shift the unstable dislocation.

Our patients pull chest expanders regularly while lying on their backs and also do manually resisted bilateral arm movements, incorporating static work for back extensors. (Fig. 2.)

In incomplete lesions we use light suspension frames, which fit over the bed, to give spring resisted exercises to recovering muscle groups in the lower limbs.

\section{Overcoming Loss of Vaso-Motor Control}

Patients with fracture dislocation of the spine usually remain immobilised in bed for three months in our Unit to allow for complete stabilisation. At the end of this period

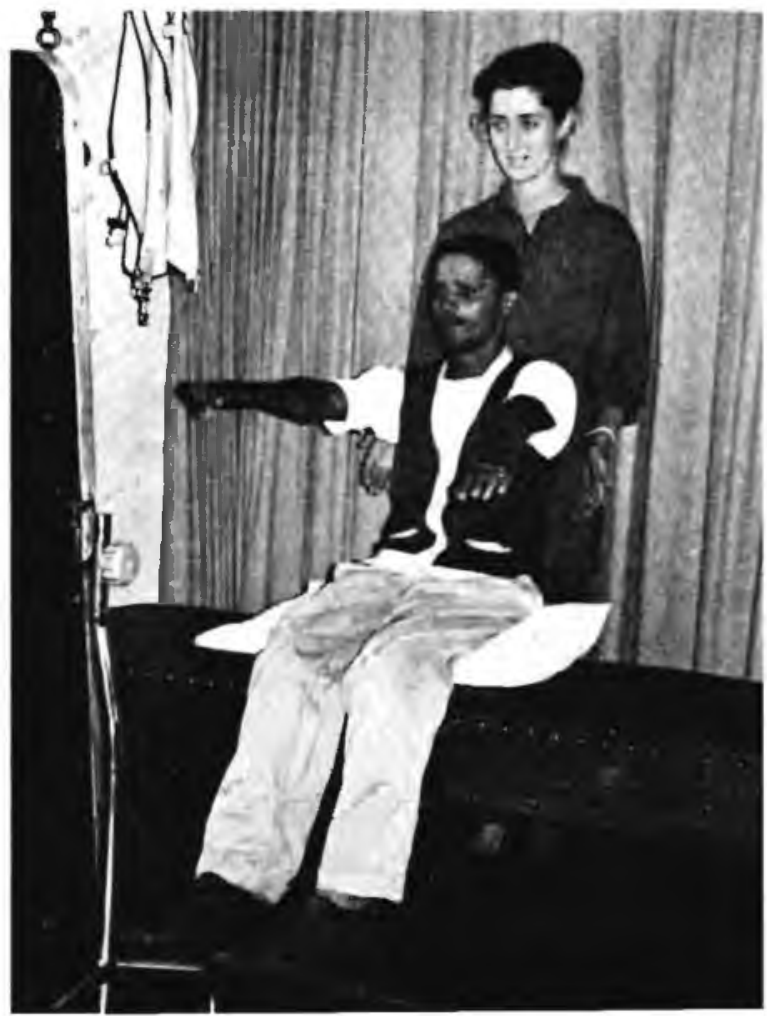

FIG. 3

Frans, a complete lesion at C7 balances in front of a mirror without spinal support.

we begin to sit them up and this may require a few days, to overcome the tendency to faint or feel dizzy. The patients are brought slowly into the sitting position on a surgical bed and it is only when they can remain in the upright position for an hour or so with no ill effects that they are ready to be lifted into a chair.

Before they are raised in this way the physiotherapist encourages the patient to do deep expiratory breathing, sometimes with manual assistance, to aid venous return She gives strong resisted exercises to the arms to draw blood to the working muscle groups and so prevent "pooling" of blood in the abdomen-the cause of fainting. The blood tends to pool as there is no vaso-constrictor tone in the blood vessels, due to the cord lesion, and it takes some time for this to adjust reflexly.

This is particularly noticeable in cervical cord lesions, and some of our patients have had to be given blood to raise their haemoglobin in order to overcome persistent fainting spells.

\section{Pressure Sores}

I do not believe that pressure sores in cases of paraplegia can be treated successfully by physiotherapy, but I mention them here as this form of treatment is frequently attempted. In our Unit, where the patients are turned regularly and nursed on foam-rubber packs (see Fig. 1) sores do not occur. Should a lazy or careless patient develop a mild abrasion while in his wheel-chair, through failing to lift, he is put to bed immediately and the area heals quickly, through relief of pressure. Since deep sinus sores, with bone infection may take years to heal, merely by relieving pressure and combating the infection, it is necessary for the plastic surgeon to treat these surgically. 


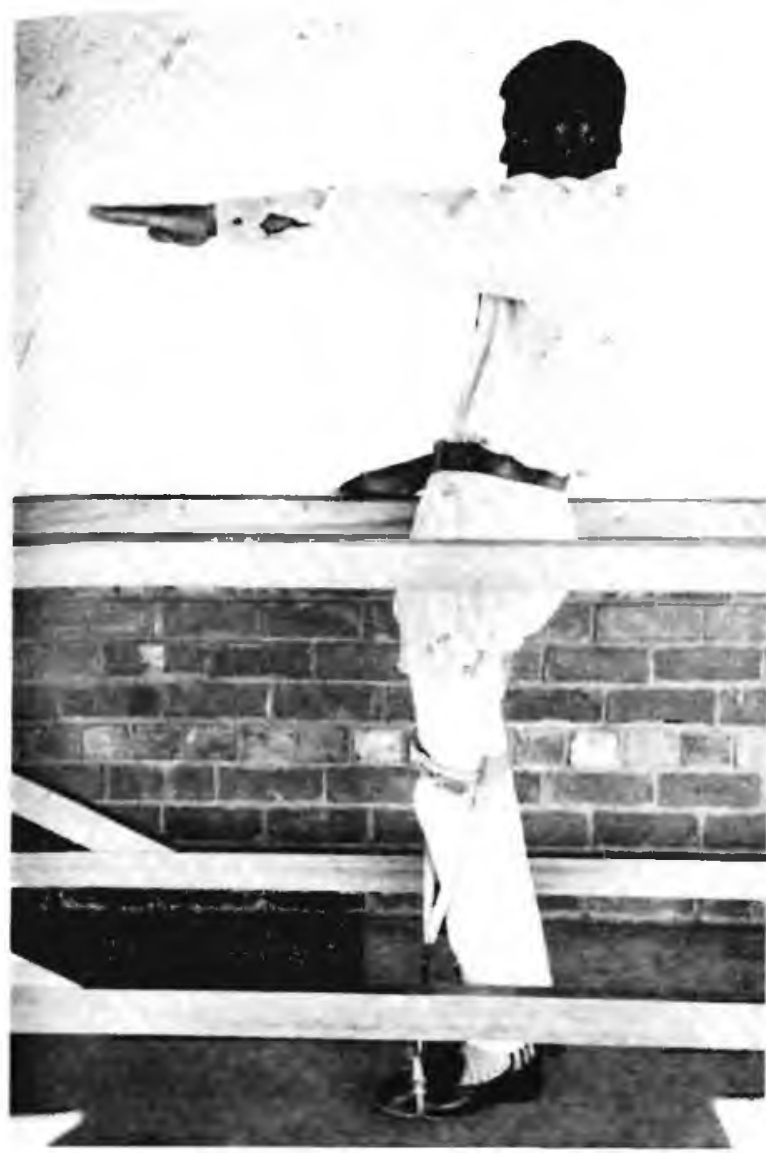

FIG. 4

Richard, supported by plaster back-slabs and toe-raising springs, balances between parallel bars by hanging on the "Y" ligaments of his hips.

\section{PART 2}

Later Treatment

\section{Relief of Pressure}

From the moment the patient starls sitting in a wheelchair we make it his responsibility to prevent pressure sores. Even quadraplegics without triceps must be taught to relieve pressure. The paraplegic is encouraged to lift his seat every ten minutes by pressing on the arms of his chair and straightening his arms. Quadraplegics are taught to relieve pressure by lifting one leg at a time or leaning over, first to one side and then to the orher.

\section{Balance}

Balance is another early lesson which must be taught. Using a mirror so that sight may take the place of lost sensation, the physiotherapist begins by teaching the patient to balance in his wheelchair, until he can do this with his eyes closed. He then learns to balance seated on a plinth (Fig. 3) progressing to being able to throw and catch a medicine ball in this position, even possible for quadraplegics. It is unnecessary for them to wear a spinal brace to maintain the upright position. Practice and careful instruction will allow even the most severely paralysed to sit unsupported. In the same way we do not use special wheelchairs for our quadraplegics. They become skilful at handling the usual chair and it is easier for later transportation and home use.
Before ordering calipers we teach the patients to stand and walk with the aid of plaster-of-paris back-slabs, reaching two inches below the ischial tuberosities to two inches above the malleoli and bandaged on with six-inch crepe bandages. This avoids the unnecessary expense of obtaining calipers for a patient who may never be able to use them successfully, due to spasm, lack of willpower, etc.

We have found the most suitable calipers are those made of light duraluminium, reaching to about four inches below the ischial tuberosities, and having knock-knee straps to prevent the medial aspect of the knee from pressing against the metal upright, and so creating a sore. Pelvic bands are unnecessary and could easily cause pressure, as well as hampering the paraplegic's ability to manoeuvre while on his feet.

The paraplegics are taught 10 walk berween parallel bars, again using mirrors. They learn 10 stand and balance by extending their hips, and hanging on the " $Y$ " ligainents of the hip joint. (Fig. 4.) We teach the four-point gait first, to strengthen the invaluable latissımus dorsi muscle. Later the "swing-to" gait is introduced, and also the "swing-through" gait which is faster and requires less effort. It is important here to delay teachıng crutch-walking untıl the patient is completely adept at walking between parallel bars and can do this without thinking about it. reflexly, as a normal person ivalks. During this time the physıotherapist hyperstrengihens his upper trunk muscles with mat exercises (crawling, press-ups etc.), spring-resisted exercises and manually-resisted exercises in diagonal patterns. We teach

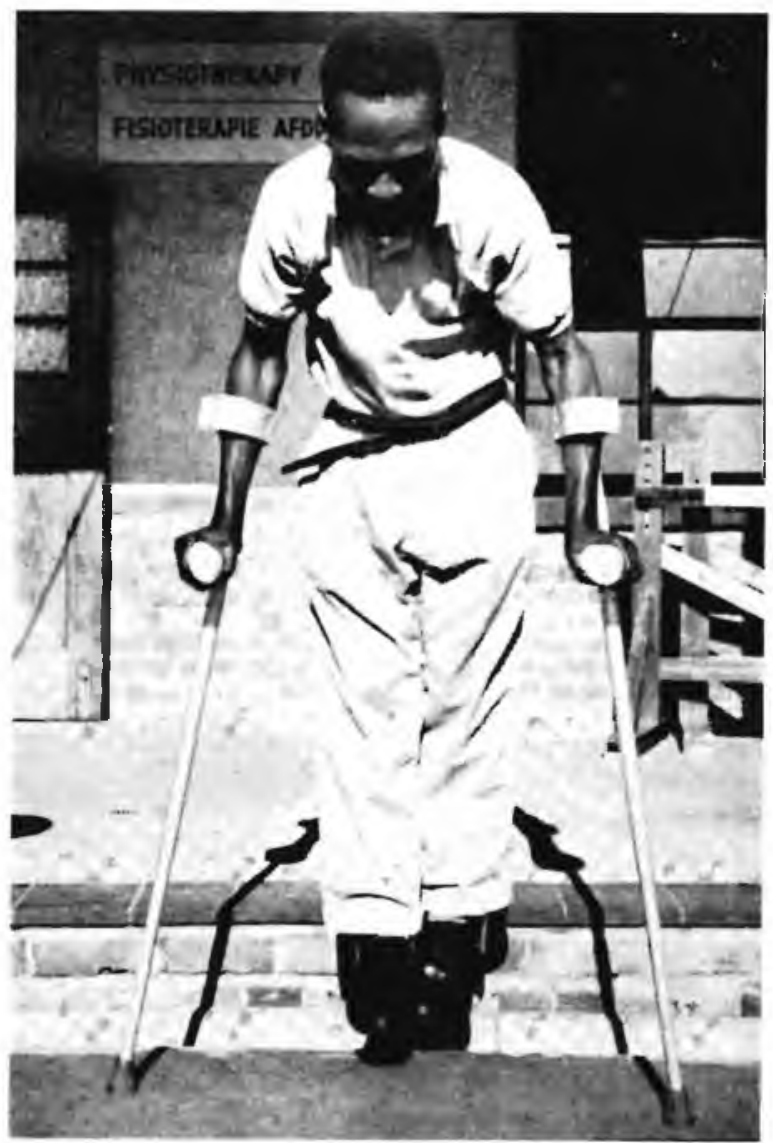

FIG. 5

Petrus, with a complete paralysis below $\mathrm{C} 7$ negotiates a step with the aid of calipers and crutches. 
all our patienis to walk with elbow-crutches, with an armband which is moveable and can lock in a horizontal position. These seem to allow for more functional activities, and eliminate the danger of "crutch palsy". We encourage even the quadraplegics to stand daily because it is therapeutic in that it prevents osteoporosis and aids bladder function, even though it is not functional. I believe that the physiotherapist should be very ambitious, even with cervical cord lesions, as I have been amazed by what they can achieve. We have at present a $\mathrm{C} 7$ lesion who walks with elbow crutches, swingthrough gait, in the ward, on the grass and even negotiates stairs. (Fig. 5.)

The patient should be taught maximum independence, e.g. climbing on and off his bed from a wheelchair, to negociate kerbs, to get in and out of a motor car unaided and to dress himself. (Fig. 6.) We find this is possible even with cervical cord lesions. There is no set routine or method of teaching these activities. The phsyiotherapist must work them out with each particular patient according to his individual needs.

Quadraplegics take about a year to rehabilitate fully, while the average low lesion may take nine months. The time naturally varies, according to the patients' rate of progress and ingenuity, but we do feel that it is a mistake to shorten the period of hospitalisation too much. They might then never reach the degree of independence possible for them.

In our Unit we work very closely with both social workers and occupational therapists during this stage of rehabilitation, to ensure that the patient will be able to do all that he will find necessary after his discharge from hospital, both at work and in his home surroundings.

I stress again the importance of team work in the successful rehabilitation of the paraplegic patient.

$$
\text { FIG. } 6
$$

Completely paraplegic below T10, Gideon shows how he climbs into a car, without using his wheelchair.

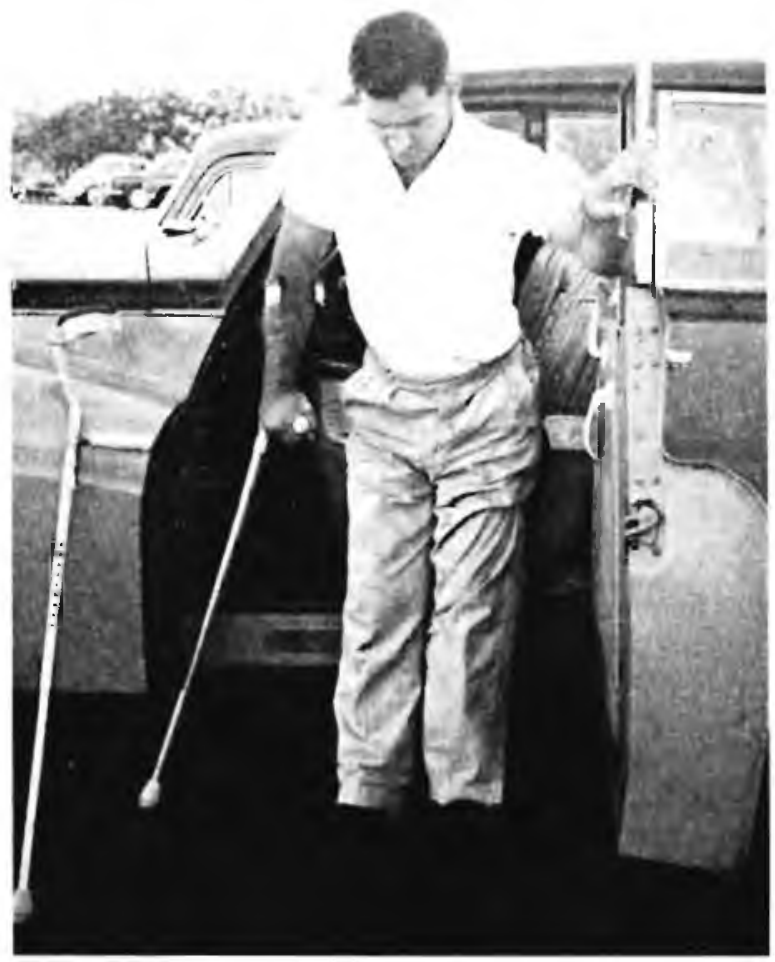

\section{THE ROSSLYN TRACTION COUCH FOR RHYTHMICAL AND SUSTAINED TRACTION}

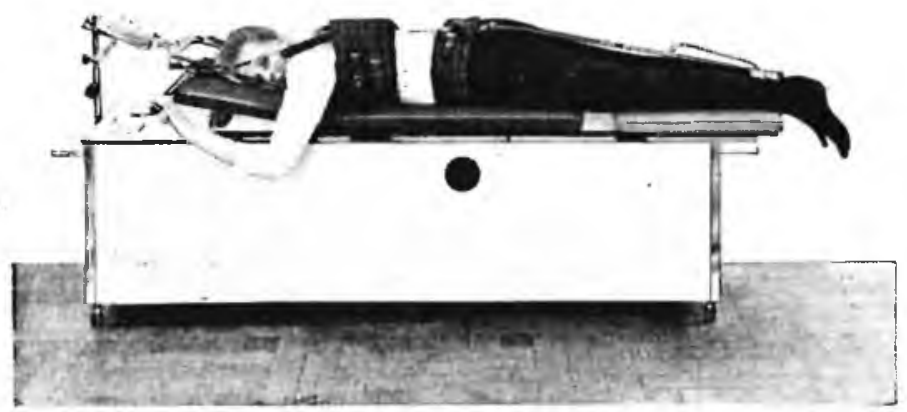

The application of controlled maximum stretch or traction, alternating with periods of complete relaxation has proved beneficial in many painful derangements of the lumbar-cervical spine.

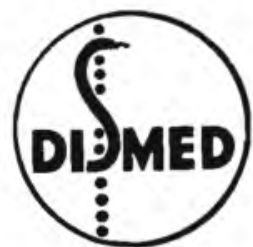

Telephone 23-8106

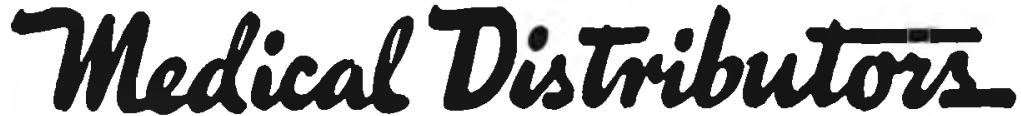

"CAPE YORK," 252 JEPPE STREET, JOHANNESBURG

and

PRESIDENT HOUSE, 20 BARRACK STREET, CAPE TOWN
(PTY.) LTD.

P.O. Box 3378

P.O. Box 195 